\title{
Performance of ecological concrete-based ecological systems (ECBESs) for nitrogen removing from synthetic farmland drainage water
}

\author{
Wei $\mathrm{Xu}^{1}{ }^{*}$, Song $\mathrm{Gao}^{1}$, Weijian Fang ${ }^{1}$, Chengcheng $\mathrm{Shi}^{1}$, Song Zhang ${ }^{1}$, Hongjian $\mathrm{Gao}^{1}$ \\ ${ }^{1}$ School of Resources \& Environment, Anhui Agricultural University, Hefei, 230036, China.
}

\begin{abstract}
Efficiency and mechanism of nitrogen removals by ecological concrete-based ecological systems (ECBESs) were investigated in this study. Results show that ECBES performed well on denitrification. Ecological concrete as matrix of the ecological was positive for nitrogen removing according to that the experimental ECBESs achieved a greater TN removal compared to the control system. This result was possibly attributable to a higher biomass and increased bacteria diversity in ECBESs, since ecological concrete could be a carrier of microorganism. Vegetation could further improve TN removals. Acorus calamus L.- ECBES, Ipomoea aquatica Forsk - ECBESs, Oenanthe javanica (Bl.) DC. - ECBES and Zizania aquatica - ECBES achieved an average TN removal of $67.87 \%, 81.93 \%, 76.18 \%, 66.22 \%$, respectively, in a test cycle. Nitrogen transformation in the ECBESs indicated the occurrence of ammonification, nitrification and denitrification. Moreover, bacteria related to nitrogen transformation was identified from the bio-film immobilized on the ecological concrete.
\end{abstract}

\section{Introduction}

Agricultural non-point source (NPS) pollution has an increasing contribution to the deterioration of aquatic environments, due to the rapid development of agriculture (Nsenga Kumwimba et al., 2018; Wang et al., 2020). Agricultural runoff originated from rainfall and irrigation is one important NPS (He et al., 2021; Yuan et al., 2019). The increased nitrogen $(\mathrm{N})$ as fertilizers has been excessively used in agriculture to achieve high food production in China (Nsenga Kumwimba et al., 2018). As a result, The loss of $\mathrm{N}$ from farmland is growing continuously; considerable amount of $\mathrm{N}$ soured from fertilizers went eventually into the aquatic environments, aggravating eutrophication of water bodies and toxic algal blooms (Cai et al., 2021).Drainage ditches, usually designed and constructed as a component of agricultural irrigation and drainage systems, are dominant pathways for NPS pollutants moving from fields to downstream water bodies ( $\mathrm{Li}$ et al., 2020). Traditional agricultural ditches are usually protected with impermeable concrete which are not plantable ( $\mathrm{Li}$ et al., 2019), and therefore are of limited efficiency in removing $\mathrm{N}$ as well as other pollutants. Ecological ditches are promising in economically and effectively reducing of farmland nutrient runoff losses (Cai et al., 2021; Li et al., 2020). Substituting ecological ditches for traditional agricultural ditches is an important way to control farmland pollutants. However, most of the present ecological ditches, which have soil as inner wall and underneath for plants growing, are poorly scouring and erosion resistant, limiting its practice application. There is an urgent need for ditches protection materials which are both solid and plantable.

Ecological concrete (eco-concrete) is a new environment-friendly material with a special structure of high porosity (Liu et al., 2021). Its abundant pores could provide more living space for plants and microorganisms (Long et al., 2017;Xie et al., 2021) as well as a passageway for transportation among water, air, soil, and plants(Maet al., 2021 ).Meanwhile, eco-concrete has a greater scouring and erosion resistanence compared to soil (Teymouri et al., 2020). More and more importance has been attached to the application of eco-concrete in recent years (Long et al., 2017; Yuan et al., 2019). Eco-concrete has been reported to be utilized for slope ecological protection ( $(\mathrm{Li}$ et al., 2019; Long et al., 2017) and road runoff purifying (Yuan et al., 2017). Application of eco-concrete in construction of ecological ditches is a feasible way for solving the problem of structural stability of ecological ditches.

Drainage ditches constructed with eco-concrete could actually be regarded as an ECBES. Investigation of the performance of ECBES for removing contaminants from farmland drainage water may provide useful information for the application of eco-concrete in ecological ditches. However, related studies are still insufficient. Since nitrogen is a main element driving water eutrophication, the objectives of this study are to:(1) explore the efficiency and mechanism of TN removals by ECBES, as well as nitrogen transformation in the system; (2) to identify the microbial communities linking to nitrogen transformation and elimination in ECBESs.

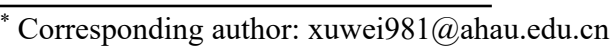




\section{Materials and methods}

\subsection{Experimental design}

A drainage ditch usually has a certain storage volume. As a result, the farmland drainage water might experience a long period of retention in the ditch (could be more than ten days) before overflowing. During farmland drainage water's retention in a ditch, pollutants elimination should be a static process. Static removals of pollutants are expected to occur at most time of a year if a drainage ditch has a large storage volume. Accordingly, this study investigated nitrogen removals under a static condition using five experimental devices described by Figure 1.The devices were made of PVC; the sizes of them were shown in Figure $1.18 \mathrm{~cm}$ of eco-concrete was laid at the bottom of each experimental device as matrix. The eco-concrete with a porosity of $20 \% \sim 35 \%$ were made with gravel (as aggregate), cement, fly ash binder, and naphthalene series water reducing agent. There were several holes in the surface of the eco-concrete layer for planting; soil was filled into the holes to fix the roots of the plants.

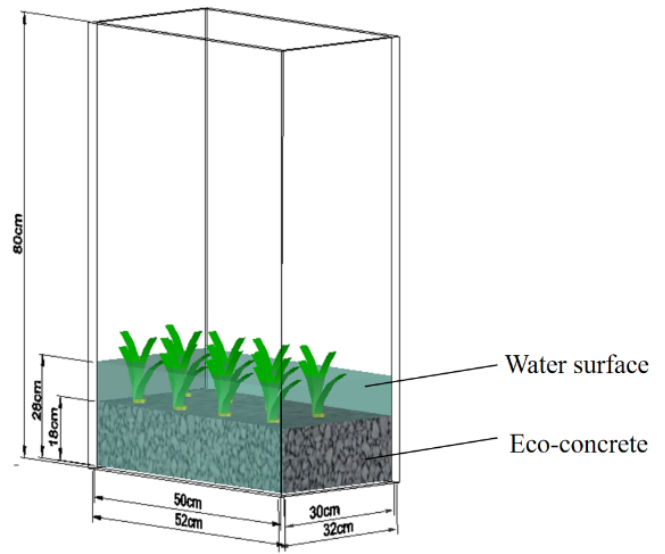

Fig. 1. Schematic diagram of the experimental device

Before planting, the experiment devices were fed with clean water continuously until $\mathrm{pH}$ of the outflow of them decreased to $8 \sim 10$, followed by adding Sulfur powder into the soil in the holes to further adjust $\mathrm{pH}$ of the cover water. The experimental devices were placed in a greenhouse. Water temperature was $27.4^{\circ} \mathrm{C} \sim 30.9^{\circ} \mathrm{C}$ during the experiment.

The experiment included five parallel test groups (A: no planting- ECBES; B: Acorus calamus L.- ECBES; C: Ipomoea aquatica Forsk - ECBES; D: Oenanthe javanica (Bl.) DC. - ECBES; E: Zizania aquatica - ECBES). Each group was in triplicate. Synthetic farmland drainage water was prepared with carbamide, $\mathrm{kH}_{2} \mathrm{PO}_{4}$, glucose as $\mathrm{N}$ source, $\mathrm{P}$ source and carbon source, respectively. The target concentrations of TN, TP, and $\mathrm{COD}_{\mathrm{Mn}}$ of the test water were $30 \mathrm{mg} / \mathrm{L}, 1.2 \mathrm{mg} / \mathrm{L}, 130 \mathrm{mg} / \mathrm{L}$ respectively. Those concentrations were at a high level for farmland drainage water according to one previous investigation. Three consecutive test cycles were conducted; each cycle lasted for 11 days according to a previous test. Water samples were withdrew from the experimental devices at a certain interval. To eliminate the effects of evaporation, distilled water was added into the experimental devices to reach a constant water level before sampling. $\mathrm{TN}, \mathrm{NH}_{4}^{+}-\mathrm{N}$, $\mathrm{NO}_{3}^{-} \mathrm{-N}$ in those water samples were measured according to Standard methods (Song, et al., 2020).

\subsection{Bio-film sampling, DNA extraction and sequencing}

Bio-film immobilized on the eco-concrete in no plantingECBES and mixed bio-film immobilized on the ecoconcrete in vegetation-ECBES, as well as suspended micro-organisms samples from the control system containing neither eco-concrete nor plants, were collected at the end of the experiment. The microbial communities in the three bio-film samples were analyzed based on metagenomic approach. DNA was extracted from each sample using Omega Mag-Bind Soil DNA Kit (Shanghai Hayan Biotechnology Co. Ltd, China) following the instructions of the manufacture. Community DNA was purified and characterized through agarose-gel electrophoresis and NanoDrop spectrophotometer. The metagenomic sequencing was performed using Illumina HiSeq 2000 platform. Metagenomic sequences were annotated using the MG-RAST automaticannotation server.

\section{Results and discussion}

\subsection{Removals of TN by ECBESs}

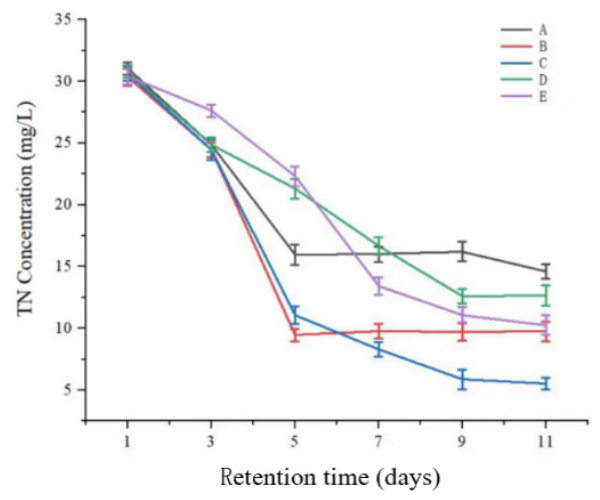

Fig. 2. Dynamic TN concentrations in experimental ECBESs during a test cycle (A:no planting; B:Acorus calamus L; C:Ipomoea aquatica Forsk; D:Oenanthe javanica (Bl.) DC.; E: Zizania aquatica )

Figure 2 presents the dynamic TN concentrations in the experimental ECBESs during a test cycle. The values of TN concentrations in Figure 2 were obtained by averaging the data of the three test cycles. Obvious TN decline over time was observed in each experimental ECBES. No planting-ECBES was evidently more effective in TN removals compared to the control group (data are not shown in this paper). One possible explanation for the result is that the eco-concrete as a carrier might have enriched those microorganisms related to denitrification (Long et al., 2017; Xie et al., 2021), enhancing the efficiency of TN removals by the ECBES. In theory, it is unlikely to form an alternation between aerobic 
environment and anoxic environment in no plantingECBES. Nevertheless, the uneven distribution of dissolved oxygen might create a local anoxic environment in the system, likely resulting in a simultaneous Nitrification and denitrification in the system.

Results show that vegetation improved the TN removals significantly, overall. No planting- ECBES, Acorus calamus L.- ECBES, Ipomoea aquatica Forsk ECBES, Oenanthe javanica (Bl.) DC. - ECBES and Zizania aquatica - ECBES achieved an average TN removal of $52.97 \%, 67.87 \%, 81.93 \%, 76.18 \%, 66.22 \%$, respectively, in a test cycle. There are four possible mechanisms for the improvement of $\mathrm{TN}$ removals by vegetation: Plants could directly assimilate $\mathrm{N}$ during its growing; roots of plants could provide more surface for microorganism to attach, increasing the biomass and bacteria diversity in the system(Long et al., 2017); aerobic respiration and oxygen release performed by plants could promote the alternation between aerobic environment and anoxic environment; root exudates might enhance the growth of heterotrophic denitrifying bacteria and shape microbial community richness and diversity(Cui et al., 2020).

\subsection{Nitrogen transformation in the experimental ECBESs}

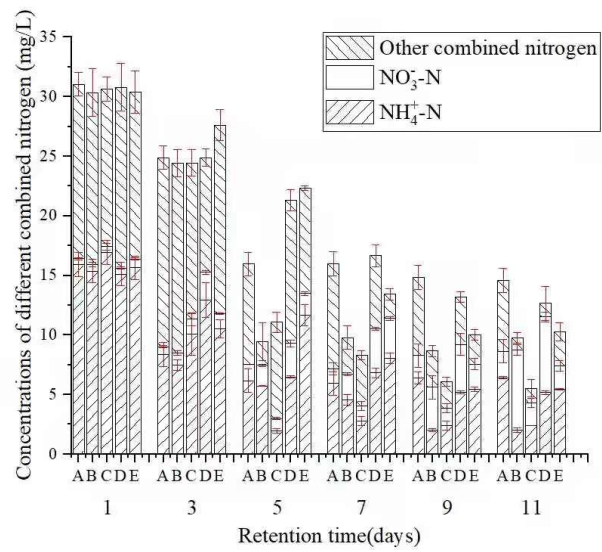

Fig. 3. Nitrogen transformation in the experimental ECBESs (A: no planting; B: Acorus calamus L; C: Ipomoea aquatica Forsk; D: Oenanthe javanica (Bl.) DC.; E: Zizania aquatica)

Nitrogen transformation in the experimental ECBESs was analyzed using the data from the third test cycle. The results are illustrated by Figure 3. Carbamide was the sole initial $\mathrm{N}$ source in the experimental ECBESs, and thus organic nitrogen should be the only component of the combined nitrogen at the beginning of the test cycle. After 1 day, substantial amount of organic nitrogen was transformed into $\mathrm{NH}_{4}^{+}-\mathrm{N}$, with $\mathrm{NH}^{+}{ }_{4}-\mathrm{N}$ accounting for $30 \%$ of the total nitrogen. Meanwhile, a small amount of $\mathrm{NO}_{3}^{-}$ $\mathrm{N}(1.43 \% \sim 2.46 \%)$ was detected in the experimental ECBESs. Hydrolysis and ammoniation are two possible mechanisms for the transformation from carbamide to ammonia. Creation of nitrate was expected to be mainly due to nitrification. It is shown by Figure 3 that the $\mathrm{NH}_{4}^{+}$ $\mathrm{N}$ concentration of each experimental ECBES decreased dramatically from the third day. The final concentrations of $\mathrm{NH}_{4}^{+} \mathrm{-N}$ of no planting-ECBES and vegetation-ECBESs were $6.42 \mathrm{mg} / \mathrm{L}$ and $1.03 \mathrm{mg} / \mathrm{L} \sim 6.33 \mathrm{mg} / \mathrm{L}$, respectively, in the test cycle. Nitrification was supposed to play a leading role in reducing ammonia according to the high $\mathrm{NH}^{+}{ }_{4} \mathrm{~N}$ removals achieved by no plantingECBES. Direct ammonia assimilation by plants improved $\mathrm{NH}^{+}{ }_{4}-\mathrm{N}$ removals to a certain extent, since the $\mathrm{NH}_{4}^{+}{ }_{4} \mathrm{~N}$ removals of vegetation-ECBESs were slightly greater than that of no planting-ECBES.

Even though considerable amount of $\mathrm{NH}^{+}{ }_{4}-\mathrm{N}$ should have been transformed into $\mathrm{NO}_{3}^{-}-\mathrm{N}$, just tiny $\mathrm{NO}_{3}^{-}-\mathrm{N}$ accumulated in the experimental ECBESs during the test, indicating that denitrification was likely to occur (since nitrate assimilation by the plants or /and microorganism is expected to have limited contribution to the $\mathrm{NO}_{3}^{-} \mathrm{N}$ removing).

\subsection{Structure of microbial communities in ECBESs}

Figure 4 shows the relative abundance of microbial community of the three samples at genus level. CK, CKEool-co, Eool-co represent the sample from the control system, the sample from no planting-ECBES and the sample from vegetation-ECBESs, respectively. The major genus in control system included Delftia, Klebsiella, Enterobacteriaceae-noname, Pseudomonas, Enterobacter, Chryseobacterium, Comamonas, and Acidovorax. Dominant species in no planting-ECBES were Enterobacter, Aeromonas, Geobacter, Azoarcus, Rhodobacte, Thiobacillus, Thauera, Thiomicrospira, Acidovorax, Sulfurospirillum, Hydrogenophaga, Chryseobacterium, Comamonas, Pseudomonas, Porphyrobacter, Fluviicola, Acinetobacter, Dechloromonas, Desulfuromonas, Lentimicrobium, Desulfovibrio, and Pseudorhodobacter. The major genus in vegetation-ECBESs were Hydrogenophaga, Thiobacillus, Geobacter, Trichococcus, Acidovorax, Youngiibacter, Comamonadaceae-noname, Bacteroidales-noname, Rhodobacter, Pseudomonas, Desulfomicrobium, Azonexus, Arenimona. Azoarcus, Desulfovibrio, and Curvibacter.

The community composition of the ECBESs showed a higher diversity at the genus compared with that of the control system. Many bacteria which have been reported to be capable of denitrifying was found in the bio-film from the experimental ECBESs, including Acidovorax, Rhodobacter, Hydrogenophaga, and Dechloromonas. There were no bacteria which have been reported to be related to nitration were found in the experimental ECBESs, except for Azoarcus. Nevertheless, creation of nitrate could be an evidence for the existence of some nitrifiers which might not be detected in the samples or not be identified yet. 


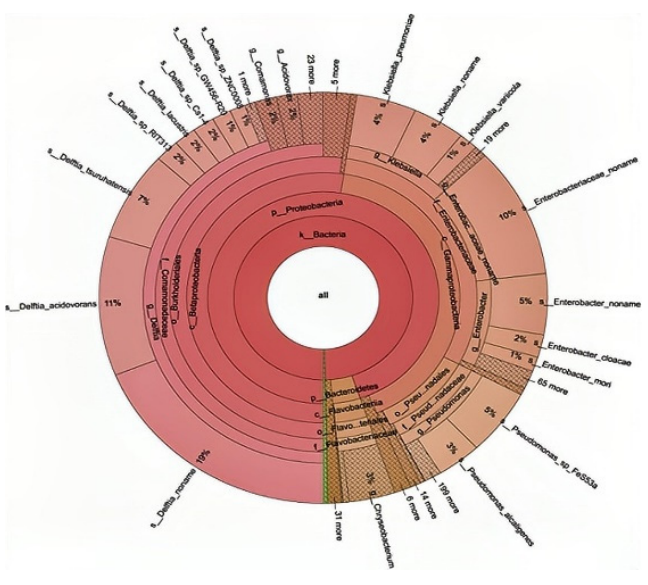

(a)CK

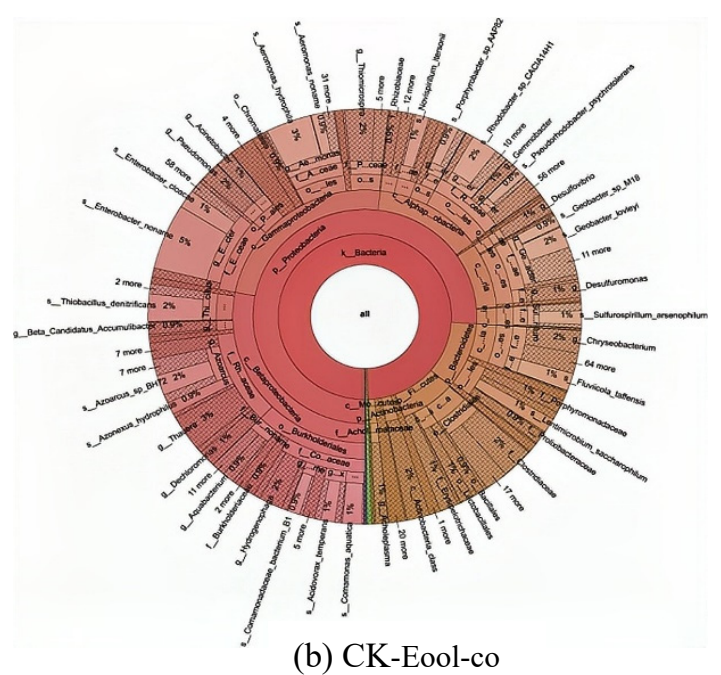

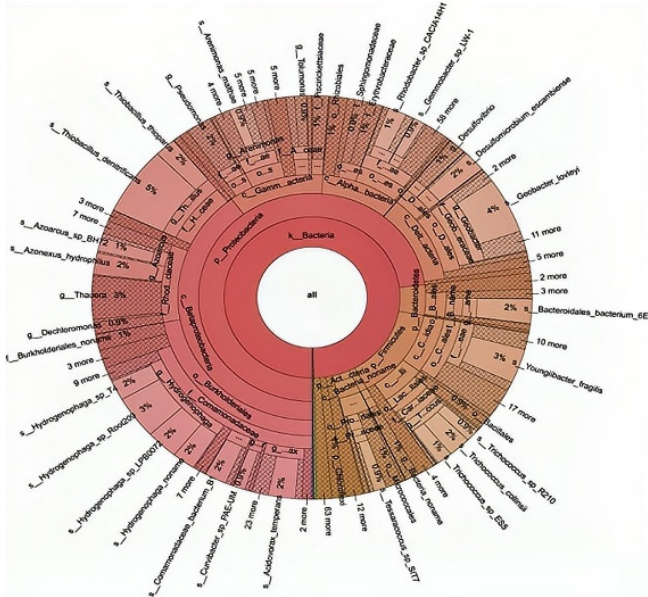

(c) Eool-co

Fig. 4. The relative abundance of microbial communities of different samples at the genus level

\section{Conclusions}

Eoncrete-based ecological systems (ECBESs) were rather effective in nitrogen removing with $\mathrm{TN}$ removals greater than $65 \%$. Eco-concrete was favourable for denitrification, according to that the TN removals of ECBESs were greater than that of the control system. This result could be explained by that porous structure of eco-concrete may provide more living space for microorganisms and therefore enhanced the biological removals of nitrogen. The community composition in ECBESs showed a higher diversity at the genus level compared to that in the control system. Vegetation could improve TN removals, which might be attributed to the enhancement of nitrification and denitrification through plants physiology processes, as well as an enrichment of microorganisms on the plants roots. Nitrogen transformation evidenced the occurrence of ammonification, nitrification and denitrification in the experimental ECBESs. Bacteria related to denitrification were found in experimental ECBESs.

\section{Acknowledgement}

This research was financially supported by the National
Key Research and Development Program of China (2018YFD0800301).

\section{References}

1. Cai, M., Zhang, X., Abdelhafez, A. A., Zhou, L., Chen, G., Zou, G., \& Cui, N.. Feasibility of improving nitrogen removal by integrating the rice straw and zeolite with drainage ditches for farmland runoff control. Environmental Technology \& Innovation, 21(4), 101359 (2021).

2. Cui, N., Zhang, X., Cai, M., Zhou, L., Chen, G., \& Zou, G.. Roles of vegetation in nutrient removal and structuring microbial communities in different types of agricultural drainage ditches for treating farmland runoff. Ecological Engineering, 155, 105941(2020).

3. He, Y., Zhou, X., Zhang, Q., Gu, J., Zhang, Y., Liu, Y., Wang, L., Xiao, Y., Shen, F., Deng, S., Zhang, S., \& Luo, L.. Highly efficient removal of phosphorus from agricultural runoff by a new akadama clay barriervegetated drainage ditch system (VDD) and its mechanism, Journal of Environmental Management, 290, 112575(2021).

4. Li, L., Zhang, H., Zhou, X., Chen, M., Lu, L., \& 
Cheng, X.. Effects of super absorbent polymer on scouring resistance and water retention performance of soil for growing plants in ecological concrete. Ecological Engineering, 138, 237-247(2019)

5. Li, X., Zhang, W., Zhao, C., Li, H., \& Shi, R.. Nitrogen interception and fate in vegetated ditches using the isotope tracer method: a simulation study in northern China. Agricultural Water Management, 228, 105893(2019)

6. Liu, L., Ji, J., Guo, Y., \& Chen, J.. Use of ecological concrete for nutrient removal in coastal sediment and its effects on sediment microbial communities. Marine Pollution Bulletin, 162, 111911 (2020).

7. Long, Y., Bing, Y., Zhang, Z., Cui, K., Pan, X., Yan, X., Li, B., Xie, S., \& Guo, Q.. Influence of plantation on microbial community in porous concrete treating polluted surface water. International Biodeterioration \& Biodegradation, 117, 8-13. (2017).

8. Ma, H., Wu, Z., Zhang, J., Yu, H., \& Liang, L.. Uniaxial compressive properties of ecological concrete: experimental and three-dimensional (3D) mesoscopic investigation. Construction and Building Materials, 278, 121034(2021).

9. Nsenga Kumwimba, M., Meng, F., Iseyemi, O., Moore, M. T., Bo, Z., Tao, W., Liang, T., \& Ilunga, L.. Removal of non-point source pollutants from domestic sewage and agricultural runoff by vegetated drainage ditches (vdds): Design, mechanism, management strategies, and future directions. Science of the Total Environment, 639, 742-759. (2018).

10. Song, J., Li, Q., Dzakpasu, M., Wang, X. C., \& Chang, N.. Integrating stereo-elastic packing into ecological floating bed for enhanced denitrification in landscape water -sciencedirect. Bioresource Technology, 299, 122601(2020).

11. Teymouri, E., Mousavi, S. F., Karami, H., Farzin, S., \& Kheirabad, M. H.. Municipal wastewater pretreatment using porous concrete containing finegrained mineral adsorbents. Journal of Water Process Engineering, 36, 101346 (2020).

12. Wang, J., Cheng, G., Fu, Z., Song, X., Yang, L., \& Liu, F. Application performance and nutrient stoichiometric variation of ecological ditch systems in treating non-point source pollutants from paddy fields. Agriculture, Ecosystems \& Environment, 299, 106989. (2020).

13. Xie, C., Yuan, L., Tan, H., Zhang, Y., Zhao, M., \& Jia, Y.. Experimental study on the water purification performance of biochar-modified pervious concrete. Construction and Building Materials, 285, 122767 (2021).

14. Yuan, D., Cui, L., An, Y., Chen, B., Guo, X., Li, Y., Zhao, R., Cui, S., Wang, S., \& Kou, Y., Investigating the pollutant-removal performance and DOM characteristics of rainfall surface runoff during different ecological concrete revetments treatment. Ecological indicators, 105, 655-662(2018).

15. Yuan, D., Guo, X., Xiong, Y., Cui, J., Yin, X., \& Li, Y... Pollutant-removal performance and variability of
DOM quantity and composition with traditional ecological concrete (TEC) and improved multiaggregate eco-concrete (IMAEC) revetment treatments. Ecological Engineering, 105, 141149(2017) 